\title{
A Randomized Prospective Study on Interlay Vs Underlay of Type I Tympanoplasty in Remote Tertiary Center
}

\author{
Md Sharif Alam ${ }^{\oplus 1}$, Om Prakash ${ }^{\circledR 2}$, R P Thakur ${ }^{\oplus 3}$ \\ ${ }^{1}$ Senior Resident, Department of ENT, Anugarah Narayan Magadh Medical College \& Hospital, Gaya, Bihar, India, ${ }^{2}$ Professor \& HOD, Department of ENT, Anugarah \\ Narayan Magadh Medical College \& Hospital, Gaya, Bihar, India, ${ }^{3}$ Associate Professor, Department of ENT, Anugarah Narayan Magadh Medical College \& Hospital, \\ Gaya, Bihar, India.
}

\section{Abstract}

Background: Type I tympanoplasty is a surgical technique used to restore the integrity of tympanic membrane as well as improve the hearing in inactive mucosal chronic otitis media. There are two main methods that are underlay and overlay in between both is interlay. The aim of the present study is to analyse and compare the results of the two most commonly used type I tympanoplasty techniques, underlay and the interlay technique in chronic otitis media with mucosal disease in large central perforation, in terms of graft uptake and hearing improvement. Subjects and Methods: This is a randomized prospective study of 100 cases of inactive mucosal chronic otitis media with total or large anterior central perforation between October2017 to September 2019 in Anugarah Narayan Magadh Medical College \& Hospital, Gaya. Half had gone through Interlay and half by Underlay technique of Type I Tympanoplasy surgery. Results: The graft uptake rate in this study was $96 \%$ and $90 \%$ for Interlay and Underlay technique respectively. Postoperatively mean air bone gap maximally reduced in the Interlay technique. Conclusion: The present study showed that Interlay method had better graft uptake rate as well as hearing improvement in total and large anterior central perforation of inactive mucosal chronic otitis media than the Underlay technique.

Keywords: Chronic otitis media, Interlay, Underlay, Type 1 tympanoplasty

Corresponding Author: Md Sharif Alam, Senior Resident, Department of ENT, Anugarah Narayan Magadh Medical College \& Hospital, Gaya, Bihar, India.

E-mail: sharifdralam@gmail.com

Received: 21 February 2020

Revised: 20 March 2020

Accepted: 27 March 2020

Published: 26 May 2020

\section{Introduction}

Perforation of the tympanic membrane is most commonly the end result of chronic middle ear infection. Other causes include trauma or iatrogenic causes. A majority of these perforations eventually heal spontaneously but the remaining chronic non healing perforations result in recurrent ear discharge and decreased hearing and will subsequently need tympanoplasty. ${ }^{[1]}$

Tympanoplasty is one of the most commonly done otological procedure. It was introduced by Berthold and further developed by Wullstein and Zollner. ${ }^{[2-4]}$ Type I tympanoplasty is surgically used to repair the tympanic membrane perforation along with improvement of hearing level in the patient. ${ }^{[5]}$

In literature many surgical techniques of tympanoplasty are described. To name a few most commonly used techniques are underlay, interlay, overlay, sandwich and double breasting techniques. ${ }^{[6-11]}$ Out of these techniques the most commonly used techniques are underlay, interlay, and overlay. Each technique has its own advantages as well as disadvantages. As per the available literature the end result of tympanoplasty depending on the graft take up rates and the hearing improvement varies between 75 to $98 \%$. These results are dependent on the surgical skill of the operating surgeon as well as on the surgical technique employed.

In underlay type I tympanoplasty the graft is placed below all the three layers. Thus there are chances of graft medialization as well as danger of residual epithelium and anterior blunting in underlay technique. ${ }^{[12]}$ Underlay technique is considered easier and faster technique with a high graft uptake rate. ${ }^{[13]}$

Interlay technique has many advantages upon the underlay technique. In it the graft is kept in between the mucosal and the fibrous layers which eventually grow on the inner and the outer surface of the graft leading to closure of the perforation. Thus this mucosal and fibrous layer plane is the most physiological plane for keeping the graft. It obviously prevents medialization 
as well as lateralization of the graft since graft is supported on both the sides by the outer fibrous and the inner mucosal layer. It also prevents any reduction of the middle ear space as well as the operating time and the healing times are short. There are very less chances of residual epithelium and anterior blunting. The interlay technique has more than $90 \%$ graft take up rate. ${ }^{[14-18]}$

\begin{abstract}
Aim
The aim of the present study is to analyse and compare the results of the two most commonly used type I tympanoplasty techniques, underlay and the interlay technique in chronic otitis media with mucosal disease in large central perforation, in terms of graft uptake and hearing improvement. The main aim is to find most effective method of tympanoplasty. Also to analyse the time taken, graft uptake and better hearing gain in rural scenario.
\end{abstract}

\section{Subjects and Methods}

\section{Study design and setting}

The present study is a randomized prospective study of 24 month duration from January 2017 to December 2019 in 100 patients of chronic otitis media inactive mucosal type with large central perforation admitted in the E.N.T department at ANMMCH, Gaya. The study was conducted after getting ethical clearance from the Ethical committee. Patients and the attendants were informed and counselled regarding the disease process, surgical procedure involved and the expected outcomes, complications and alternative treatments available. Written and informed consent was taken from the patient as well as the attendant.

\section{Study period}

The duration of study was two year from January 2017 to December 2019. The follow up period was 3 months.

\section{Sample size}

100 patients from the outpatient department of E.N.T at the ANMMCH, Gaya. Randomly 50 patients were included in each group i.e. underlay group (Group 1) and interlay group (Group 2). Results were calculated in terms of graft take up rate and hearing improvement.

\section{Inclusion criteria}

Cases of chronic otitis media with inactive mucosal disease with a large central perforation and pure conductive hearing loss were included in the study. The ear was dry for at least 6 weeks. Both males and females in the age group of 10 to 60 years of age were included in the study.

\section{Exclusion criteria}

Following patients were excluded from the study- Patients with active mucosal disease; patients with squamosal disease; patients with ossicular discontinuity/ necrosis; patients with tympanosclerosis; patients with sensorineural and mixed hearing loss; patients below 10 years and above 60 years were excluded from the study; patients with diabetes mellitus, hypertension and other systemic diseases; patients with active focus of infection in throat, nose and oral cavity; patients with recurrent disease (revision cases); patients who fail to followup for at least 3 months.

\section{$\underline{\text { Procedure }}$}

All these cases were undergone a detailed workup which included relevant history of the disease, thorough clinical examination of ear, nose, and throat along with routine laboratory investigations.

Ear examination including examination under microscope, tuning fork tests, pure tone audiometry, and radiological tests (X-ray mastoid - Schuller's view) were done in all cases. Informed consent was obtained from all the patients as well as the attendants.

Pre-operatively all patients had pure tone audiogram with an average of four frequencies $0.5,1,2,4 \mathrm{Khz}$ calculated for both the air and the bone conduction.

All the cases were performed under general anesthesia, through postaural approach and using temporalis fascia graft. In all these cases, posterior meatotomy was done followed by freshening of margins.

Underlay technique was done in 50 randomly selected patients having dry ear. Surgery was done by conventional method using temporalis fascia graft. After conforming ossicular mobility graft was placed under the remnant of drum after elevating the tympanomeatal flap along with the annulus.

Interlay technique was done in 50 randomly selected patients. Tympanomeatal flap was elevated all around up to the level of the fibrous annulus, preserving superiorly, in the region of head of malleus. After raising tympanomeatal flap fibrous annulus was taken out of the bony sulcus all around, thus fibrous and squamoual layers were lifted off the tympanic membrane remnants along with the annulus, keeping the mucosal layer intact. Ossicular mobility was checked and confirmed.

Temporalis fascia graft was harvested dried in room air. It was grafted, under the malleus handle, and resting on the bony canal walls all around and supported by the remnant mucosal layer below. The tympanomeatal flap was reposited back. The graft was covered with blood and antibiotic solution soaked gelfoams and a medicated ointment pack was kept in 
the external auditory canal for 1 week.

All the patients were followed up on a regular basis, i.e., after end of 1st week, four weeks, eight weeks, and 12 weeks. At every follow up, oto-microscopy was done to check the graft uptake and complication (if any). Post- operatively a pure tone audiogram using $(0.5 / 1 / 2 / 4 \mathrm{Khz})$ was performed at the end of three months. Hearing results were assessed by comparing pre-operative and postoperative pure tone averages as well as closure of the air-bone gap.

Standard statistical analysis was done and statistical package for the social sciences (SPSS) Software was used to analyse the data.

\section{Results}

Out of 100 cases enrolled in the study, randomly 50 patients were taken for underlay and 50 were taken for interlay technique and comprised group 1 and 2 of the study respectively. Age of patients ranged from 10 to 60 years. Left ear was operated in $55(55 \%)$ patients while right ear was operated in the remaining $45(45 \%)$ cases. Mean age of patients in groups 1 and 2 were $33.12 \pm 10.294$ and $31.86 \pm 10.11$ years respectively.

In group1, a total of $26(52 \%)$ patients were males and remaining $24(48 \%)$ were females and in group 2, $29(58 \%)$ patients were males and remaining $21(42 \%)$ were females showing a slight male preponderance but it was statistically in significant. [Chi-square $=1.36$ with 1 degree of freedom; $\mathrm{p}=0.05(\mathrm{NS})$ ]

\section{Mean hearing gain (Closure in air-bone gap)}

Preoperative mean air bone gap in groups 1 and 2 was $26.3 \pm 8.50$, and $25.5 \pm 8.16 \mathrm{~dB}$ and postoperative mean air bone gap was $17.6 \pm 8.762$ and $13.5 \pm 5.369 \mathrm{~dB}$ [Table 4].

In both the groups a significant mean reduction in air bone gap was observed. Mean reduction was maximum in group 2. Statistically, intergroup difference in reduction in air bone gap was highly significant $(\mathrm{p}<0.001)$

\section{Graft status (accepted or rejected)}

In the present study Graft failure was observed in 7 cases (7\%) resulting in a residual perforation. Success rate was $90 \%$ and 96\% in Underlay (group 1) and Interlay (group 2) respectively. Least graft failure rate (4\%) was found in group 2 [Table 5].

\section{Discussion}

India is one of the countries with highest load of chronic otitis media. ${ }^{[19]}$ It is important being a curable cause of deafness. It is the end result of acute otitis media and is characterized by a persistent discharge from the middle ear through a tympanic membrane perforation.
Tympanoplasty is the operative procedure performed to repair the perforation in ear drum by repairing the tympanic membrane. ${ }^{[3]}$ It is a beneficial procedure to protect the middle ear and inner ear from future damage. Improvement in hearing sensitivity is also observed. ${ }^{[20]}$

There are many approaches to perform this procedure. Out of these the Underlay technique is widely used.

Recently a new technique, Interlay has also emerged and is being successfully used worldwide with very good results. The differences in immediate success rates and resultant hearing gain are comparable in both the techniques. ${ }^{[8,12]}$

In our study, in Underlay technique graft rejected in 5 patients. Preoperative mean air bone gap was $26.30 \mathrm{~dB}$ and postoperatively it came to be $17.60 \mathrm{~dB}$. Postoperatively there was an $8.70 \mathrm{~dB}$ mean hearing gain after 12 weeks.

In interlay technique graft rejected in 2 patients. Preoperative mean air bone gap was $25.5 \mathrm{~dB}$ which comes to be $13.50 \mathrm{~dB}$. Postoperative there was change in $12.0 \mathrm{~dB}$ mean hearing gain after 12 weeks.

No complication was noticed in any of the two procedures. The final success rate was $90 \%$ in Underlay and $96 \%$ in Interlay technique.

Thus in present study as far as resolution of air bone gap is concerned, Interlay technique showed a statistically significant better outcome as compared to the underlay group. The findings in present study showed a better graft take in Interlay method which coupled with a better post- operative air bone gap provided a better overall outcome.

Preoperative mean air bone gap in groups 1 and 2 was $26.30 \pm 8.50 \mathrm{~dB}$ and $25.50 \pm 8.16 \mathrm{~dB}$ and postoperative mean air bone gap was $17.60 \pm 8.762 \mathrm{~dB}$ and $13.50 \pm 5.369 \mathrm{~dB}$ [Table 4].

In our study graft uptake as well as hearing gain was better in the interlay technique than the underlay technique which was consistent with most of the studies. Jain et al had graft uptake rate to be $96.6 \%$ in interlay technique and $95.4 \%$ of the patients, reported an improvement in terms of hearing. [7] Kawatra et al concluded Interlay technique has a significantly better graft uptake and hearing improvement as compared to underlay technique. ${ }^{[8]}$ Komune et al reported a 94.2\% graft uptake rate. ${ }^{[14]}$ Guo et al had a better graft uptake rate and hearing improvement in interlay technique than in underlay technique. ${ }^{[15]}$ Patil et al had a graft uptake rate of $96 \%$ and a significant haring gain in interlay technique. ${ }^{[18]}$

\section{Conclusion}

The present study showed that Interlay technique had a better graft take and hearing improvement than the underlay technique. These results indicate that interlay is a better 
Table 1: Age distribution of study subjects

\begin{tabular}{lllllll}
\hline Age in years & Underlay (Group 1) & \multicolumn{2}{l}{ Interlay (Group 2) } & Total & \\
& $\mathbf{N}$ & $\mathbf{\%}$ & $\mathbf{N}$ & $\mathbf{\%}$ & $\mathbf{N}$ & $\mathbf{\%}$ \\
$10-20$ & 4 & 8 & 5 & 10 & 9 & 9 \\
$21-30$ & 20 & 40 & 22 & 44 & 42 & 42 \\
$31-40$ & 15 & 30 & 13 & 26 & 28 & 28 \\
$41-50$ & 8 & 16 & 9 & 18 & 17 & 17 \\
\hline $51-60$ & 3 & 6 & 1 & 2 & 4 & 4 \\
Total & 50 & 100 & 50 & 100 & 100 & 100 \\
\hline
\end{tabular}

Chi-square $=1.408$ with 4 degrees of freedom; ${ }^{*} \mathrm{p}=0.842$ (NS).

Table 2: Preoperative air-bone gap of the patients

\begin{tabular}{l|ll|ll}
\hline Preoperative & Group 1 (underlay) & Percentage & Group 2 (interlay) & \\
& No. & \% & No. & \% \\
\hline $10-20$ & 13 & 26 & 14 & 28 \\
\hline $21-30$ & 20 & 40 & 22 & 44 \\
$31-40$ & 12 & 24 & 11 & 22 \\
\hline 40 & 5 & 10 & 3 & 6 \\
\hline
\end{tabular}

Table 3: Postoperative air-bone gap of the patients

\begin{tabular}{|c|c|c|c|c|}
\hline \multirow[t]{2}{*}{ Postoperative } & \multicolumn{2}{|c|}{ Group 1 (underlay) } & \multicolumn{2}{|c|}{ Group 2 (interlay) } \\
\hline & No. & $\%$ & No. & $\%$ \\
\hline$<10$ & 20 & 40 & 24 & 48 \\
\hline $11-20$ & 15 & 30 & 17 & 34 \\
\hline $21-30$ & 10 & 20 & 6 & 12 \\
\hline $31-40$ & 4 & 8 & 2 & 4 \\
\hline$>40$ & 1 & 2 & 1 & 2 \\
\hline
\end{tabular}

Table 4: Change in air bone gap in both groups at 12 weeks follow up.

\begin{tabular}{|c|c|c|c|c|c|c|}
\hline \multirow[t]{2}{*}{ Groups } & \multicolumn{2}{|c|}{ Preoperative } & \multicolumn{2}{|c|}{ Post-operative } & \multirow{2}{*}{$\begin{array}{l}\text { Change } \\
\text { Mean }\end{array}$} & \multirow{2}{*}{$\begin{array}{l}\text { Significance of } \\
\text { change } \\
\text { P value }\end{array}$} \\
\hline & Mean & SD & Mean & SD & & \\
\hline $\begin{array}{ll}\text { Group } & 1 \\
\text { (Underlay) } & \end{array}$ & 26.3 & 8.50 & 17.60 & 8.762 & -8.7 & $<0.001$ \\
\hline $\begin{array}{l}\text { Group } 2 \text { (Inter- } \\
\text { lay) }\end{array}$ & 25.5 & 8.16 & 13.5 & 5.369 & -12 & $<0.001$ \\
\hline
\end{tabular}

Table 5: Outcome of graft at 12 weeks follow up.

\begin{tabular}{llrll}
\hline Parameter/ variable & \multicolumn{2}{l}{ Group 1 (underlay) } & $(\mathbf{n}=\mathbf{5 0})$ & \multicolumn{2}{l}{ Group 2 (interlay) $(\mathbf{n}=\mathbf{5 0})$} \\
& No. & $\mathbf{\%}$ & No. & $\mathbf{\%}$ \\
Rejected/failed & 5 & 10 & 2 & 4 \\
Accepted/successful & 45 & 90 & 48 & 96 \\
\hline
\end{tabular}


approach than the underlay type I tympanoplasty in chronic otitis media with large central perforation of mucosal variety.

\section{References}

1. Galdstone HB, Jackler RK, Varav K. Tympanic Membrane Wound Healing. An Overview. Otolaryngol Clin North Am. 1995;28(5):913-945.

2. Berthold E. Overlay myringoplasty. Wier Med Bull. 1878;1:627-627.

3. WULLSTEIN H. THEORY AND PRACTICE OF TYMPANOPLASTY. Laryngoscope. 1956;66(8):1076???10931076???1093. Available from: https://dx.doi.org/10.1288/ 00005537-195608000-00008. doi:10.1288/00005537195608000-00008.

4. Zollner F. The principles of plastic surgery of the soundconducting apparatus. J Laryngol Otol. 1955;69:637-52.

5. Aslam MA, Aslam MJ. Comparison of Over- Underlay and Underlay Techniques of Myringoplasty. Pak Armed Forces Med J. 2009;59(2):155-161.

6. Shea JJ. Vein Graft Closure Of Eardrum Perforations. J Laryngol Otol. 1960;74(6):358-362. Available from: $\quad$ https://dx.doi.org/10.1017/s002221510005670x. doi:10.1017/s002221510005670x.

7. Gupta R, Jain S, Gupta N, Roy A. Interlay Type I tympanoplasty in large central perforations: Analysis of 500 cases. Indian J Otol. 2017;23(1):32-32. Available from: https://dx.doi.org/10.4103/0971-7749.199503. doi:10.4103/0971-7749.199503.

8. Kawatra R, Maheshwari P, Kumar G. A Comparative study of the techniques of Myringoplasty - Overlay Underlay \& Interlay. IOSR J Dent Med Sci. 2014;13(12):12-16. Available from: https://dx.doi.org/10.9790/0853-131251216. doi:10.9790/0853-131251216.

9. House WF. Myringoplasty. Archives Otolaryngol Head Neck Surg. 1960;71(3):399-404. Available from: https://dx.doi.org/10.1001/archotol.1960.03770030041009. doi:10.1001/archotol.1960.03770030041009.

10. Karlan MS. Gelatin Film Sandwich in Tympanoplasty. Otolaryngol Head Neck Surg. 1979;87(1):84-86. Available from: https://dx.doi.org/10.1177/019459987908700120. doi:10.1177/019459987908700120.

11. Juvekar MR, Jurekar RV. The double breasting technique of tympanoplasty: A study of 200 cases. Indian J Otol. 1999;5:145-153.

12. Kartush JM, Michaelides EM, Becvarovski Z, LaRouere MJ. Over-Under Tympanoplasty. Laryngoscope. 2002;112(5):802807. Available from: https://dx.doi.org/10.1097/00005537-
200205000-00007. doi:10.1097/00005537-200205000-00007.

13. Singh M, Rai A, Bandyopadhyay S, Gupta SC. Comparative study of the underlay and overlay techniques of myringoplasty in large and subtotal perforations of the tympanic membrane. J Laryngol Otol. 2003;117(6):444-448. Available from: https://dx.doi.org/10.1258/002221503321892262. doi:10.1258/002221503321892262.

14. Komune S, Wakizono S, Hisashi K, Uemura T. Interlay Method for Myringoplasty. Auris Nasus Larynx. 1992;19(1):1722. Available from: https://dx.doi.org/10.1016/s0385-8146(12) 80197-0. doi:10.1016/s0385-8146(12)80197-0.

15. Guo M, Huang Y, Wang J. Report of Myringoplasty with interlay method in 53 ears perforation of tympani. Lin Chuang Er Bi Yan Hou Ke Za Zhi. 1999;13(4):147-156.

16. Sengupta A, Basak B, Ghosh D, Basu D, Adhikari D, Maity K. A Study on Outcome of Underlay, Overlay and Combined Techniques of Myringoplasty. Indian J Otolaryngol Head Neck Surg. 2012;64(1):63-66. Available from: https://dx.doi.org/10. 1007/s12070-011-0257-z. doi:10.1007/s12070-011-0257-z.

17. Hay A, Blanshard J. The anterior interlay myringoplasty: Outcome and hearing results in anterior and subtotal tympanic membrane perforations. Otol Neurotol. 2014;35(9):1569-76.

18. Patil BC, Misale PR, Mane RS, Mohite AA. Outcome of Interlay Grafting in Type 1 Tympanoplasty for Large Central Perforation. Indian J Otolaryngol Head Neck Surg. 2014;66(4):418-424. Available from: https://dx.doi.org/10. 1007/s12070-014-0741-3. doi:10.1007/s12070-014-0741-3.

19. Nardone M, Sommerville R, Bowman J, Danesi G. Myringoplasty in simple chronic otitis media: critical analysis of longterm results in a 1,000-adult patient series. Otol Neurotol. 2012;33(1):48-53.

20. Hussain A, Yousaf N, Khan AR. Outcome of Myringoplasty. J Postgrad Med Inst. 2004;18:693-699.

Copyright: (C) the author(s), 2020. It is an open-access article distributed under the terms of the Creative Commons Attribution License (CC BY 4.0), which permits authors to retain ownership of the copyright for their content, and allow anyone to download, reuse, reprint, modify, distribute and/or copy the content as long as the original authors and source are cited.

How to cite this article: Alam MS, Prakash O, Thakur RP. A Randomized Prospective Study on Interlay Vs Underlay of Type I Tympanoplasty in Remote Tertiary Center. Acad. J Surg. 2020; 3(1):26-30.

DOI: dx.doi.org/10.47008/ajs/2020.3.1.6

Source of Support: Nil, Conflict of Interest: None declared. 